\title{
THE REVIEW OF COMPARED PROGESTINS TYPE AND DOSE UTILITY AGAINST THE PITUITARY SUPPRESSION DURING OVARIAN STIMULATION FOR ASSISTED REPRODUCTIVE TECHNOLOGY
}

\author{
ALEXANDRU POLEXA ${ }^{1}$, SEBILE GULER CEKIC ${ }^{2}$, SULE YILDIZ $^{3}$, ENGIN TURKGELDI $^{4}$ \\ BARIS ATA ${ }^{5}$
}

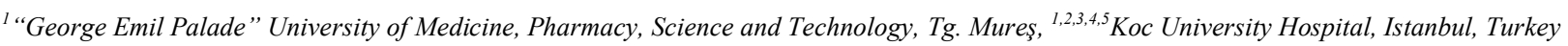

Keywords: $\quad$ progestins, Abstract: We performed a literature review of studies comparing the effectiveness of progestins in ovarian stimulation, IVF, preventing premature ovulation during ovarian stimulation for assisted reproductive technology assisted reproduction (ART). Five randomized trials and cohort studies involving a total of 2404 women, which compared; i) two different progestins or ii) two different doses of the same progestin were included. The primary outcome was live birth rate (LBR) per woman. Secondary outcomes were live birth or ongoing pregnancy $(L B / O P)$ per woman and per embryo transfer (ET), ongoing pregnancy, clinical pregnancy, positive pregnancy test, numbers of oocytes and metaphase-two oocytes, duration of stimulation and gonadotropin consumption. The primary outcome was not reported in most studies however there were no differences between progestins for secondary outcomes. All progestins seem to effectively prevent premature ovulation in ART cycles. Low-quality evidence suggests that progestins can effectively prevent premature ovulation in ART cycles.

\begin{abstract}
INTRODUCTION
Pituitary suppression is required to decrease the risk of ovulation before oocyte retrieval (OR) in assisted reproduction technology (ART) cycles. Currently, gonadotropin releasing hormone $(\mathrm{GnRH})$ analogues are the standard of care for pituitary suppression.(1) However, progestins are also capable of suppressing endogenous luteinizing hormone (LH) secretion from the pituitary. $(2,3,4,5)$ The advent of oocyte and embryo vitrification techniques coupled with increasing use of a freeze all strategy in assisted reproductive technology cycles led to increasing use of progestins for pituitary suppression.

Available evidence suggests progestins are as effective as GnRH analogues and may even yield more oocytes.(6) However, there is limited information about the effectiveness of different progestins or different dosages of the same progestin.
\end{abstract}

\section{AIM}

This narrative review proposed to explore the literature for studies comparing clinical outcomes of ART cycles using progestins for pituitary suppression.

\section{MATERIALS AND METHODS}

We searched for studies, which compared; i) two different progestins or ii) two different doses of the same progestin for pituitary suppression in ART. Only studies published in English as a full text article were included. Protocols of incoming studies, cross-over trials, case reports, comments, editorials, and letters were excluded.

The primary outcome was live birth of a fetus after 20 completed weeks of gestational age per woman starting a stimulation cycle.

Secondary outcomes were i) live birth or ongoing pregnancy beyond 12 weeks per woman starting a stimulation cycle, ii) live birth rate per embryo transfer procedure, iii) live birth or ongoing pregnancy per embryo transfer procedure, iv) clinical pregnancy (defined as evidence of a gestational sac at six weeks or later, confirmed with ultrasound) rate per embryo transfer procedure, v) number of oocytes retrieved per OR, vi) number of metaphase two oocytes per OR, vii) the duration of a stimulation cycle, viii) total gonadotropin consumption per stimulation cycle.

Adverse events included; i) ectopic pregnancy per embryo transfer, ii) miscarriage per pregnancy: defined as the number of spontaneous abortions (pregnancy loss before 20 completed weeks of gestation) and the number of stillbirths (pregnancy loss after 20 completed weeks of gestation), iii) multiple pregnancy rate per embryo transfer.

We searched the public electronic resources as databases, trial registers and websites from the date of inception until June 1, 2019.

\section{RESULTS}

The electronic search returned 375 potential citations. After removing the duplicates 320 citations were screened and 305 were excluded by the title or abstract. Fifteen were assessed in full text. One of them was a protocol for an incoming RCT and two of the studies were irrelevant to this review. In total, one prospective cohort (7), one retrospective cohort (8) and three RCTs $(2,9,13)$ were included.

'Corresponding author: Alexandru Polexa, Str. Stefan cel Mare, Nr. 2, Bl. 10, Sc. B, Ap. 11, Braşov, E-mail: polexa a@yahoo.com, Phone: +40744 125195

Article received on 20.03.2020 and accepted for publication on 28.05.2020 


\section{CLINICAL ASPECTS}

The five studies involved a total of 2404 patients. $(2,7,8,9)$ Three studies compared two different progestins: medroxyprogesterone acetate (MPA) versus dydrogesterone (DYG) (9), DYG versus micronized progesterone (MIP) (7) and MPA versus MIP (8), two studies compared two different dosages of the same progestin (4 versus $10 \mathrm{mg}$ of MPA (2), and $100 \mathrm{mg}$ versus $200 \mathrm{mg}$ of MIP (figure no. 1).(10)

\section{Figure no. 1. Flowchart of the study}

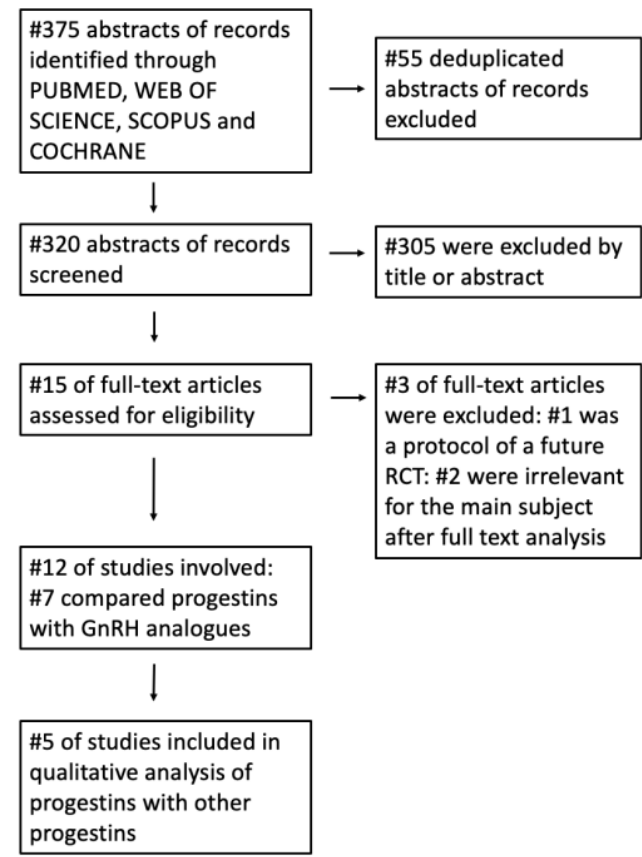

In all of the included studies, progestins were started simultaneously with gonadotropins $(150-225 \mathrm{IU} /$ day $\mathrm{hMG}$ or rFSH) on cycle day two or three. Comparisons included: 20 $\mathrm{mg}$ /day DYG with $100 \mathrm{mg}$ /day MIP (7), $20 \mathrm{mg}$ /day DYG with $10 \mathrm{mg} /$ day MPA (9), $10 \mathrm{mg}$ /day MPA with $200 \mathrm{mg}$ MIP (8), 100 $\mathrm{mg}$ with $200 \mathrm{mg} /$ day MIP (10), $4 \mathrm{mg}$ /day and $10 \mathrm{mg} /$ day MPA (table no. 1).(2)

Table no. 1. Characteristics of included studies

\begin{tabular}{|c|c|c|c|c|c|}
\hline Title & $\begin{array}{c}\text { Type } \\
\text { of } \\
\text { study }\end{array}$ & $\begin{array}{c}\text { Inclusion } \\
\text { criteria }\end{array}$ & Exclusion criteria & $\begin{array}{l}\text { Study } \\
\text { group }\end{array}$ & $\begin{array}{l}\text { Control } \\
\text { group }\end{array}$ \\
\hline $\begin{array}{l}\text { Zhu } \\
2017 \\
\text { b }\end{array}$ & RCT & $\begin{array}{ll}- & \text { Age }<40 \\
& \text { years } \\
- & \text { AFC }>4 \\
- & \text { FSH }<10 \\
& \text { IU } / \mathrm{L}\end{array}$ & $\begin{array}{ll}- & \text { PCOS } \\
\text { - } & \text { Endometriosis } \geq \\
& \text { Grade } 3 \\
& \text { Hormonal } \\
\text { treatments in the } \\
\text { previous } 3 \text { months } \\
\text { - } & \text { Any functional } \\
\text { ovarian cyst with } \\
\mathrm{E}_{2}>100 \mathrm{pg} / \mathrm{ml} \\
\text { - } \\
\text { Any } \\
\text { contraindications } \\
\text { to ovulation } \\
\text { stimulation } \\
\end{array}$ & $\begin{array}{l}\text { DYG 20 } \\
\text { mg } \\
\text { Trigger: } \\
\text { Triptorelin } \\
0.1 \mathrm{mg} \\
\mathrm{n}=125\end{array}$ & $\begin{array}{l}\text { MIP } 100 \\
\text { mg } \\
\text { Trigger: } \\
\text { Triptorelin } \\
0.1 \mathrm{mg} \\
\mathrm{n}=125\end{array}$ \\
\hline $\begin{array}{l}\text { Yu } \\
2018\end{array}$ & RCT & $\begin{array}{ll}\text { - } & \text { Age }<36 \\
& \text { years } \\
\text { - } & \text { AMH }>1 \\
\text { - } & \text { First } \\
& \text { IVF/ICS } \\
\text { - } \quad \text { Tubal } \\
\text { - } \\
\text { factor } \\
\text { BMI } 18- \\
26 \mathrm{~kg} / \mathrm{m}^{2}\end{array}$ & $\begin{array}{ll}- & \text { PCOS } \\
\text { - } & \text { Endometriosis } \geq \\
& \text { Grade } 3 \\
\text { - } & \text { Major uterine or } \\
& \text { ovarian } \\
& \text { abnormalities } \\
\text { - } & \text { Endocrine or } \\
& \text { metabolic } \\
\text { abnormalities }\end{array}$ & $\begin{array}{l}\text { DYG 20 } \\
\text { mg } \\
\text { Trigger: } \\
\text { triptorelin } \\
0.1 \mathrm{mg}+ \\
\text { hCG } 1000 \\
\text { IU } \\
n=260\end{array}$ & $\begin{array}{l}\text { MPA } \\
\text { 10mg } \\
\text { Trigger: } \\
\text { triptorelin } \\
0.1 \mathrm{mg}+ \\
\text { hCG } 1000 \\
\text { IU } \\
\mathrm{n}=256\end{array}$ \\
\hline
\end{tabular}

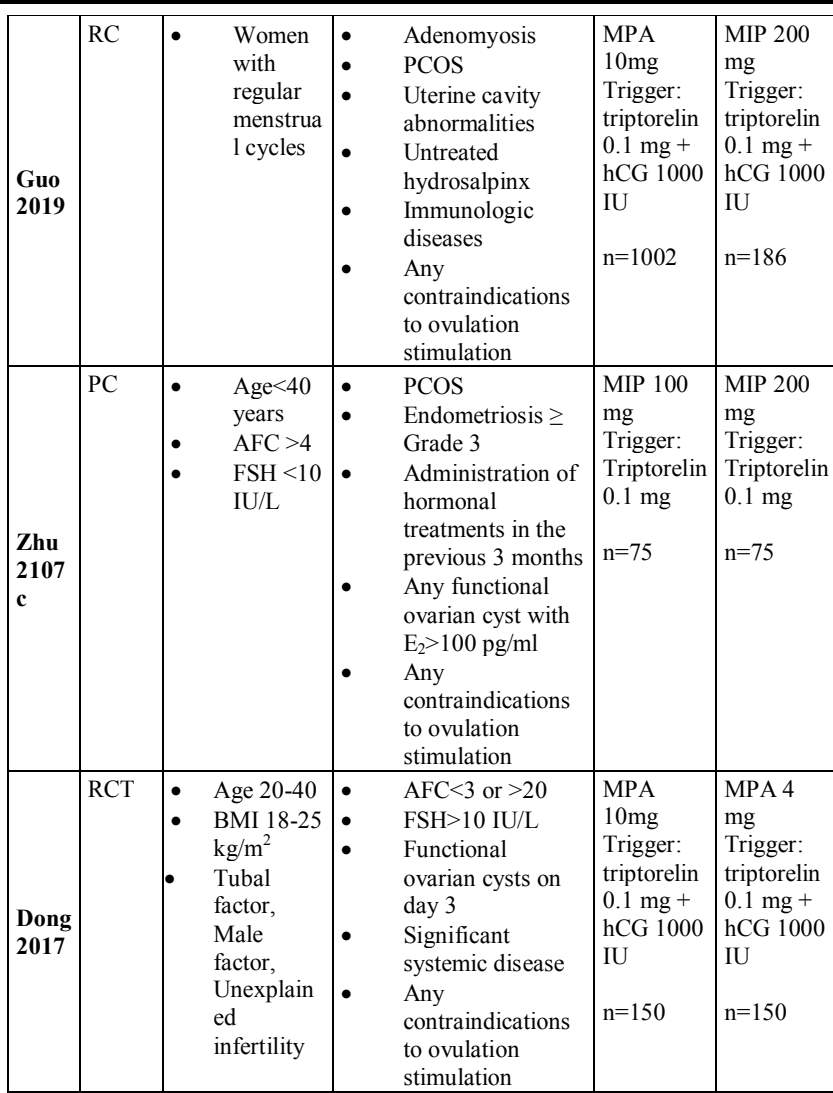

In four studies, good quality embryos were frozen at the cleavage stage, and poor-quality embryos were left for extended culture to blastocyst stage. Only embryos reaching good quality blastocysts were later frozen. $(2,9,7,10)$ In the other study, two good quality embryos were cryopreserved at cleavage stage and left all the rest to extended culture, those reaching good quality blastocysts were later cryopreserved.(8)

\section{DISCUSSIONS}

The results of our review show that there is limited information about the effectiveness of different progestins for pituitary suppression. However, DYG, MIP and MPA all seem to effectively prevent premature ovulation in ART cycles.

The dosage of progestins in the original studies have been selected somewhat arbitrarily, and later studies comparing lower dosages with the initially employed higher dosages, reported similar clinical outcome, suggesting MPA is similarly effective at $4 \mathrm{mg} /$ day as it is at $10 \mathrm{mg} /$ day (moderate quality evidence based on one RCT, requiring replication of the finding) and MIP is similarly effective at $100 \mathrm{mg} /$ day and $200 \mathrm{mg}$ /day (low to very low quality evidence based on a single retrospective cohort study) dosages. It should be noted that 100 $\mathrm{mg} / \mathrm{d}$ MIP required shorter stimulation and less gonadotropin than $200 \mathrm{mg} / \mathrm{d}$ dosage. This could suggest that milder suppression of endogenous gonadotropins with lower progestin dosage can be advantageous by not only avoiding the cost and inconvenience of $\mathrm{GnRH}$ analogue injections but also by decreasing exogenous gonadotropin consumption. Alternatively, progestins can be started later in the cycle. Indeed, Yildiz et al. started progestin on the 7th day of stimulation or when the leading follicle reached $14 \mathrm{~mm}$, rather than starting simultaneously with gonadotropins at the beginning of stimulation, and collected more oocytes than collected with a flexible GnRH antagonist cycle.(6) Yildiz et al.'s results suggest that the suppression of endogenous gonadotropins later in the cycle can yield more oocytes.

One of the suggested advantages of progestins is their 


\section{CLINICAL ASPECTS}

low cost. The only study on the cost-effectiveness of progestins as an alternative to $\mathrm{GnRH}$ analogue use for pituitary suppression has shown that when freezing all embryos were planned, progestin cycles cost $\$ 2079$ less than GnRH antagonist cycles but $\$ 823$ more than short agonist cycles per live birth.(11) However, these figures should be taken with caution since the study was done in the United States and medication and procedure costs vary greatly among countries. $(11,12)$

However, we present an unbiased overview of the current literature and identify gaps in knowledge for future research.

\section{CONCLUSIONS}

In conclusion, also if future high-quality trials confirm the assumptions of this study, progestins in general can become a reasonable alternative to GnRH analogues in ART cycles when a fresh embryo transfer is not intended.

The presence of a limited number of trials/studies, most of which are not randomized nor accounts for every woman starting stimulation are drawbacks, preventing definitive conclusions on the subject.

\section{REFERENCES}

1. Al-Inany HG, Youssef MA, Ayeleke RO, Brown J, Lam WS, Broekmans FJ. Gonadotrophin-releasing hormone antagonists for assisted reproductive technology. Cochrane Database Syst Rev. 2016;4, p CD001750. doi:10.1002/14651858.CD001750.pub4 Retrieved from https://www.ncbi.nlm.nih.gov/pubmed/27126581.

2. Dong J, Wang Y, Chai WR, Hong QQ, Wang NL, Sun LH, Kuang HP. The pregnancy outcome of progestin-primed ovarian stimulation using 4 versus $10 \mathrm{mg}$ of medroxyprogesterone acetate per day in infertile women undergoing in vitro fertilisation: a randomised controlled trial. BJOG. 2017;124(7):1048-1055. doi:10.1111/14710528.14622 Retrieved

from https://www.ncbi.nlm.nih.gov/pubmed/28276192.

3. Ubaldi FM, Capalbo A, Vaiarelli A, Cimadomo D, Colamaria S, Alviggi C, Rienzi L. Follicular versus luteal phase ovarian stimulation during the same menstrual cycle (DuoStim) in a reduced ovarian reserve population results in a similar euploid blastocyst formation rate: new insight in ovarian reserve exploitation. Fertil Steril. 2016;105(6):1488-1495

doi:10.1016/j.fertnstert 2016.03 .002 https://www.ncbi.nlm.nih.gov/pubmed/27020168.

4. Zhu X, Ye H, Fu Y. The Utrogestan and hMG protocol in patients with polycystic ovarian syndrome undergoing controlled ovarian hyperstimulation during IVF/ICSI treatments. Medicine (Baltimore. 2016;95(28):e4193. doi:10.1097/MD.0000000000004193 Retrieved from https://www.ncbi.nlm.nih.gov/pubmed/27428219.

5. Zhu X, Ye H, Fu Y. Comparison of neonatal outcomes following progesterone use during ovarian stimulation with frozen-thawed embryo transfer. Sci Rep. 2017;7(1):7835. doi:10.1038/s41598-017-08472-2 Retrieved from https://www.ncbi.nlm.nih.gov/pubmed/28798414.

6. Yildiz S, Turkgeldi E, Angun B, Eraslan A, Urman B, Ata, B. Comparison of a novel flexible progestin primed ovarian stimulation protocol and the flexible gonadotropinreleasing hormone antagonist protocol for assisted reproductive technology. Fertil Steril. 2019;112(4):677683. doi:10.1016/j.fertnstert.2019.06.009 Retrieved from https://www.ncbi.nlm.nih.gov/pubmed/31371053.

7. Zhu X, Ye H, Fu Y. Duphaston and human menopausal gonadotropin protocol in normally ovulatory women undergoing controlled ovarian hyperstimulation during in vitro fertilization/intracytoplasmic sperm injection treatments in combination with embryo cryopreservation. Fertil Steri. 2017;108(3):505-512 e502. doi:10.1016/j.fertnstert.2017.06.017 Retrieved from https://www.ncbi.nlm.nih.gov/pubmed/28697910.

8. Guo YC, Chen PY, Li TT, Jia L, Sun P, Zhu WS. Liang X. Y. Different progestin-primed ovarian stimulation protocols in infertile women undergoing in vitro fertilization/intracytoplasmic sperm injection: an analysis of 1188 cycles. Arch Gynecol Obstet. 2019;299(4):12011212. doi:10.1007/s00404-019-05065-4 Retrieved from https://www.ncbi.nlm.nih.gov/pubmed/30852654

9. Yu S, Long H, Chang HY, Liu Y, Gao H, Zhu J, Ai A. New application of dydrogesterone as a part of a progestinprimed ovarian stimulation protocol for IVF: a randomized controlled trial including 516 first IVF/ICSI cycles. Hum Reprod. 2018;33(2):229-237. doi:10.1093/humrep/dex367 Retrieved from https://www.ncbi.nlm.nih.gov/pubmed/29300975.

10. Zhu X, Ye H, Fu Y. Use of Utrogestan during controlled ovarian hyperstimulation in normally ovulating women undergoing in vitro fertilization or intracytoplasmic sperm injection treatments in combination with a "freeze all" strategy: a randomized controlled dose-finding study of 100 mg versus $200 \mathrm{mg}$. Fertil Steril. 2017;107(2):379-386 e374. doi:10.1016/j.fertnstert.2016.10.030 Retrieved from https://www.ncbi.nlm.nih.gov/pubmed/27865446.

11. Evans MB, Parikh T, DeCherney AH, Csokmay JM, Healy, MW, Hill MJ. Evaluation of the cost-effectiveness of ovulation suppression with progestins compared with $\mathrm{GnRH}$ analogs in assisted reproduction cycles. Reprod Biomed Online. 2019;38(5):691-698. doi:10.1016/j.rbmo.2018.12.044 Retrieved from https://www.ncbi.nlm.nih.gov/pubmed/30926176.

12. Iwami $\mathrm{N}$, Kawamata $\mathrm{M}$, Ozawa $\mathrm{N}$, Yamamoto $\mathrm{T}$, Watanabe E, Moriwaka O, Kamiya H. (2018). New trial of progestin-primed ovarian stimulation using dydrogesterone versus a typical GnRH antagonist regimen in assisted reproductive technology. Arch Gynecol Obstet. 2018;298(3):663-671. doi:10.1007/s00404-018-4856-8 Retrieved from https://www.ncbi.nlm.nih.gov/pubmed/30069600.

13. La Marca A, Capuzzo M. Use of progestins to inhibit spontaneous ovulation during ovarian stimulation: the beginning of a new era? Reprod Biomed Online. 2019;39(2):321-331. doi:10.1016/j.rbmo.2019.03.212 Retrieved from https://www.ncbi.nlm.nih.gov/pubmed/31138494. 